\title{
Japanese normative set of 359 pictures
}

\author{
TAKEHIKO NISHIMOTO, KAORI MIYAWAKI, TAKASHI UEDA, and YUKO UNE \\ Waseda University, Tokyo, Japan \\ and \\ MASARU TAKAHASHI \\ Saitama Institute of Technology, Saitama, Japan
}

\begin{abstract}
This study provides Japanese normative measures for 359 line drawings, including 260 pictures (44 redrawn) taken from Snodgrass and Vanderwart (1980). The pictures have been standardized on voice key naming times, name agreement, age of acquisition, and familiarity. The data were compared with American, Spanish, French, and Icelandic samples reported in previous studies. In general, the correlations between variables in the present study and those in the other studies were relatively high, except for name agreement. Naming times were predicted in multiple regression analyses by name agreement. The full set of the norms and the new pictures may be downloaded from www.psychonomic.org/archive/.
\end{abstract}

An increasing number of cognitive psychologists have shown an interest in pictorial stimuli developed for cognitive experiments. Snodgrass and Vanderwart (1980) presented a normative picture set of 260 line drawings of common objects that has helped in the investigation of such operations as encoding, storage, and retrieval processes. Using the 250 pictures from the original set of Snodgrass and Vanderwart, Snodgrass and Yuditsky (1996) reported age-of-acquisition (AoA) ratings, naming times, and correct naming rates. They showed that naming times were predicted in multiple regression analyses by name agreement (NA) or concept agreement, AoA ratings, word frequency (FREQ) taken from Kučera and Francis (1967), and familiarity (FAM) taken from Snodgrass and Vanderwart. They compared voice key and keypress responses and suggested that the former worked remarkably well as an indicator of naming difficulty.

Pictorial stimuli have been standardized in different languages. For example, Alario and Ferrand (1999) collected French normative data for the 400 pictures used by Cycowicz, Friedman, Rothstein, and Snodgrass (1997), which included the 260 pictures in Snodgrass and Vanderwart (1980). Bonin, Peereman, Malardier, Méot, and Chalard (2003) presented a new French set of 299 pictures

This work was supported, in part, by the Japan Society for the Promotion of Science under Grant JSPS 15530477 and by Waseda University under Research Grants 2000B-007 and 2002A-515. The authors express their grateful acknowledgments to Jonathan Vaughan, editor of this journal, for his encouraging advice and thank two reviewers for their constructive and helpful suggestions for the first version of the manuscript. Correspondence concerning this article should be addressed to T. Nishimoto, Department of Psychology, School of Letters, Arts, and Sciences, Waseda University, 1-24-1 Toyama, Shinjuku-ku, 162-8644 Tokyo, Japan (e-mail: nishi@waseda.jp).

Note-This article was accepted by the previous editor, Jonathan Vaughan. for psycholinguistic studies. Dell'Acqua, Lotto, and Job (2000) collected Italian normative data for 266 pictures that were different from those in Snodgrass and Vanderwart, although some pictures were conceptually similar to those in Snodgrass and Vanderwart. Sanfeliu and Fernandez (1996) and Cuetos, Ellis, and Alvarez (1999) have obtained Spanish normative data. Pind, Jónsdóttir, Gissurardóttir, and Jónsson (2000) and Pind and Tryggvadóttir (2002) presented Icelandic norms for the Snodgrass and Vanderwart pictures. Bates et al. (2003) studied timed picture naming in seven languages. They used 520 line drawings, including 174 from the original Snodgrass and Vanderwart set.

In Japan, Nishimoto and Yasuda (1982), Matsukawa (1983), and Nishimoto and Hayashi (1996) obtained Japanese data, using almost the same procedures as Snodgrass and Vanderwart (1980). Nishimoto and Yasuda reported that some of the original pictures were not recognizable for Japanese participants, mainly because the pictures (e.g., thimble, artichoke, seal, caterpillar, and saltshaker) were not typical or familiar to them. For example, thimble was recognized as trash can, and artichoke as bud. Therefore, Nishimoto and Hayashi redrew 44 pictures. They also added 99 new pictures. In the study, a total of 143 pictures were standardized for the Japanese, following the procedure used in Snodgrass and Vanderwart. Nishimoto and Yasuda collected four measures - that is, NA, image agreement, conceptual FAM, and visual complexity. For newly added or redrawn pictures in Nishimoto and Hayashi, the same measures, except visual complexity, were collected. However, one of the deficits in Nishimoto and Hayashi's study was that a standardized measure of naming time was not obtained.

The present study has three goals. First, we provide a Japanese standardized set of 359 pictures, including 216 pictures from Snodgrass and Vanderwart (1980) and 143 from Nishimoto and Hayashi (1996), with an emphasis 
on naming time data. Following Snodgrass and Yuditsky (1996), four measures-NA, conceptual familiarity, naming time, and AoA - are to be standardized. NA, image agreement, conceptual FAM, and visual complexity, which constituted the principal norms in Snodgrass and Vanderwart, have been collected for the original 260 pictures in Nishimoto and Yasuda (1982). In the present study, we measured naming time and AoA, which had not been collected in Japanese standardization, in addition to FAM and NA.

Second, we make a cross-cultural comparison with previous foreign picture standardization studies. Third, we also consider whether naming time could be predicted by one or more independent variable(s). For this purpose, we used FREQ data taken from Amano and Kondo (2000), which are discussed in more detail in the Method section.

\section{METHOD}

\section{Participants}

One hundred twenty Waseda University students participated in the naming procedure, divided into three groups of 40 each. In the FAM rating procedure, 139 students were divided into three groups: 49 for Set 1, 40 for Set 2, and 50 for Set 3. In the AoA rating procedure, 149 students were divided into three groups: 54 for Set 1 , 46 for Set 2, and 49 for Set 3 . All participation was voluntary. The participants were randomly assigned to groups, and no participants took part in more than one procedure in the experimental session.

\section{Stimuli and Apparatus}

The stimuli were 260 pictures from Snodgrass and Vanderwart's (1980) set (44 redrawn) and 99 pictures newly added for the Japanese population. Appendix A shows the dominant names and norms. Appendix B shows the redrawn and newly added pictures. The 359 pictures were numbered from 1 to 359 according to Japanese Kana order (syllabary). In accordance with Snodgrass and Yuditsky's (1996) procedure, we divided the pictures into three sets on the basis of the picture number: If the remainder was 1 when the picture number was divided by 3 , the picture was assigned to Set 1 ; if the remainder was 2, the picture was assigned to Set 2; otherwise, the picture was assigned to Set 3 . Thus, 120 pictures were in Set 1 and Set 2, and 119 were in Set 3 (see Appendix A). In the naming task, the participants wore a headset microphone connected to a voice key. An MS-DOS-based computer program automatically controlled the presentation of the pictures and the voice key recording. Pictures were presented in black and white in the center of a CRT computer monitor. The pictures were $400 \times 300$ pixels, presented $60-80 \mathrm{~cm}$ away from the participant, at a visual angle of $11^{\circ}-15^{\circ}$.

\section{Procedure}

Naming procedure. The participants were asked to articulate the name of the presented picture as quickly and accurately as possible, via the headset microphone. Each trial was run as follows. The signal, "get ready," was displayed for $500 \mathrm{msec}$, followed by a blank screen for $500 \mathrm{msec}$, and then a picture was presented. When the participant made a response or $10 \mathrm{sec}$ had elapsed, the picture was erased. Then the response time (RT) and feedback from the experimenter of "correct," "error," or "voice key error" were displayed. After 20 practice trials, the experimental session, consisting of 120 trials (or 119 trials for Set 3), was presented. A short break was given after every 30 trials. Because, as Székely et al. (2003) have pointed out, the presentation order confounds naming time, the order of picture presentation was randomized for each participant. Three buffer trials were presented immediately before the start of the main trials and after each break. The pictures used in the practice trials and in the buffer trials were taken from a set of pictures that were not assigned to that participant.

Familiarity rating. The participants rated the FAM of the concepts depicted in the pictures. The participants were given a booklet including the pictures, their dominant names obtained from Nishimoto and Yasuda (1982) and Nishimoto and Hayashi (1996), and FAM scales. Pictures in the booklet were randomly ordered across participants. The participants were instructed to judge how familiar the concept was on a 7-point scale (extremely unfamiliar to extremely familiar). If they did not know the object, they were asked to respond "don't know the object." It was emphasized that the participants should rate the FAM of the concept that the picture represented, not the picture itself.

Age-of-acquisition rating. The participants rated the AoA for the concept depicted in the pictures. Booklets including the pictures, their dominant names, and AoA scales were given to the participants. The order of the items was randomized across participants. The dominant names for the pictures were obtained from Nishimoto and Yasuda (1982) and Nishimoto and Hayashi (1996). Similar to Carroll and White (1973a, 1973b), the participants were instructed to estimate when they had learned the concept, using a 9-point scale (2 years, 3 years, 4 years, 5 years, 6 years, 7-8 years, 9-10 years, 11-12 years, and 13 years or older). They were asked to rate the concept that the picture represented, not the picture itself.

\section{RESULTS AND DISCUSSION}

\section{Two Criteria for Naming Correctness}

To determine how accurately the participants named the pictures, both strict and liberal criteria for naming correctness were applied, although Snodgrass and Yuditsky (1996) suggested using only liberal criteria. A name response was judged as strictly correct if it satisfied any one of the following conditions: (1) It was the same as the correct notation (i.e., the most frequently given name in Nishimoto and Yasuda, 1982, and in Nishimoto and Hayashi, 1996); (2) it was a part of the correct notation (e.g., shirt for dress shirt or finger for index finger); (3) it was an abbreviated word starting with the same phoneme as the correct notation (e.g., heri for herikoputâ [helicopter]); (4) it was the first word of a correct notation including two or more words (e.g., ashi for ashi-no-yubi [toe]); (5) it was an idiomatic name subsuming the correct notation (e.g., happa for ha [leaf] or chouchou for chou [butterfly]); or (6) it was the more authentic name (e.g., seiyo-nashi for nashi [pear]). We regarded the name response as liberally correct when at least 2 participants named the same word for a picture, even when it was a wrong answer.

\section{Exclusion of Naming Data Outliers}

Before conducting the analyses, the naming data of some of the participants were excluded as outliers. First, the data of the participants whose naming correctness was below $75 \%$, using the strict criteria, were excluded. Second, the data of the participants whose naming time deviated more than two standard deviations $(S D \mathrm{~s})$ from the mean naming time in each set were excluded. The remaining naming data in each set and summary statistics are as follows: Set $1, n=34$, mean naming correctness (strict criteria) $=81.2 \%$, mean naming time $(S D)=1,148 \mathrm{msec}$ (401); Set 2, $n=26$, mean naming correctness (strict criteria) $=80.5 \%$, mean naming time $(S D)=1,101 \mathrm{msec}$ 
(372); Set 3, $n=23$, mean naming correctness (strict criteria) $=79.4 \%$, mean naming time $(S D)=1,171 \mathrm{msec}$ (422). ${ }^{1}$

\section{Equivalence of Sets}

As was described above, a total of 359 pictures were divided into three sets, and the participants were assigned randomly to each set. In accordance with Snodgrass and Yuditsky (1996), the equivalence of the three sets was checked in terms of naming times. Analyses of variance on the sets and the participant groups were conducted separately. The results showed that there were no significant differences among the sets or groups [for picture sets, $F(2,356)=0.954, p=.39$; for participant groups, $F(2,80)=0.733, p=.48]$. Therefore, the three sets were merged in subsequent analyses.

\section{Naming Failures}

We classified naming failures into the following four types. (1) DKO (don't know object), where the participants did not know what the picture depicted; $0.88 \%$ of the responses fell into this category. (2) DKN (don't know name), where the participants knew the object depicted but did not know what it was called, which made up $1.05 \%$ of the responses. (3) TOT (tip of the tongue), where the participants knew the object but the name was on "the tip of the tongue" and could not be recalled within the allotted time, which made up $0.84 \%$ of the responses. (4) ERROR, where the voice key malfunctioned or there was unexpected activation due to the participant's coughing, stammering, and so forth, which made up $2.16 \%$ of the responses.

\section{Measures for Standardization}

Response time (strict/liberal, trimmed RT). Mean RT for a picture was computed by deleting RTs that exceeded two SDs from the mean, because these trimmed RTs have an advantage in split-half reliability (Snodgrass \& Yuditsky, 1996). $\mathrm{RT}_{\text {st }}$ is the mean RT calculated on the basis of trimmed RTs for a dominant name according to the strict criteria in picture naming, and $\mathrm{RT}_{\text {lib }}$ is the one for both dominant and nondominant names according to the liberal criteria.

Name agreement. NA was computed using the strict and liberal criteria. $\mathrm{NA}_{\mathrm{st}}$ is the percentage of participants giving the same name as a dominant name, using the strict criteria, and $\mathrm{NA}_{1 \mathrm{ib}}$ is the percentage when the liberal criteria are used.

$\boldsymbol{H}$. A measure for name disagreement, called $H$, reported by Snodgrass and Vanderwart (1980) was calculated. $H$ is defined as

$$
H=\sum_{i=1}^{k} P_{i} \log _{2}\left(1 / P_{i}\right),
$$

where $k$ is the number of different names produced for a picture and $P_{i}$ is the proportion of participants producing the $i$ th name. Different from measures of NA $\left(\mathrm{NA}_{\mathrm{st}}\right.$ and $\mathrm{NA}_{\text {lib }}$ ), $H$ takes into account the frequency distribution and number of alternative names for a picture. $H$ is the same as $U$, the measure of codability of a stimulus (Snodgrass \& Yuditsky, 1996).

Familiarity and age of acquisition. The participants rated the FAM of each picture on a 7-point scale. The mean FAM was computed for all of the pictures. We also computed the mean AoA, on the basis of the 9-point scale.

Frequency. The FREQ for the name of each picture was determined from Amano and Kondo (2000), the most recent and one of the most exhaustive corpuses for Japanese naming words. They used articles published during 1985-1998 in Asahi-Shimbun, one of the major newspapers in Japan: the corpus consists of around 13.9 million sentences (equal to around 1.2 GB of text data). If a picture had two or more "correct" names, using the strict criteria, the frequency of that picture was defined as the total of the frequencies for these names. LogFREQ, the transformed measure of FREQ, is computed by the formula $\log (1+x)$. When a picture has one or more homonyms, FREQ could not be collected, because the FREQ of such an item was summed with other concepts having the same phonemes in the database. FREQ could be collected for 236 pictures with no homographic names.

Number of morae. We collected the number of morae (MORA) of each name. Mora is a Japanese speech unit, which approximately corresponds to a syllable in English.

\section{Correlations Among Measures}

Table 1 shows correlations among the measures (i.e., $\mathrm{RT}_{\mathrm{st}}, \mathrm{RT}_{\text {lib }}, \mathrm{NA}_{\mathrm{st}}, \mathrm{NA}_{\mathrm{lib}}$, AoA, FAM, H, FREQ, LogFREQ, and MORA). In calculating the correlations on FREQ and LogFREQ, only 236 pictures mentioned above were included. Almost all the correlations among variables were statistically significant. As was expected, $H$ and $\mathrm{NA}_{\text {st }}$ were highly correlated negatively, because $H$ represents name disagreement, on the one hand, and $\mathrm{NA}_{\mathrm{st}}$ represents name agreement, on the other hand. In addition, $H$ and RT showed a positive correlation. Similar to Snodgrass and Yuditsky (1996), FAM was negatively correlated with AoA. AoA was correlated positively with RT and $H$.

\section{Correlations With Preceding Studies}

The data were compared with those in the studies of American English (Snodgrass \& Vanderwart, 1980; Snodgrass \& Yuditsky, 1996), French (Alario \& Ferrand, 1999), Spanish (Cuetos et al., 1999), and Icelandic (Pind et al., 2000). Correlations were calculated using the data for the original pictures of Snodgrass and Vanderwart. As is shown in Table 2, almost all the correlations are statistically significant. The correlations of FAM and of AoA are higher than those of the other variables. Correlations concerning NA are relatively low, especially the correlation between Japanese $\mathrm{NA}_{\text {lib }}$ and Spanish NA, which did not reach significance. With regard to this finding, Dell'Acqua et al. (2000) suggested that measures of NA depend on language more than do the other measures. However, FAM does not depend as much on linguistic aspects, because it was rated on the basis of the picture 
Table 1

Correlations Among the Measures

\begin{tabular}{|c|c|c|c|c|c|c|c|c|c|c|}
\hline & $\mathrm{RT}_{\mathrm{st}}$ & $\mathrm{RT}_{\text {lib }}$ & $\mathrm{NA}_{\mathrm{st}}$ & $\mathrm{NA}_{\text {lib }}$ & $H$ & AoA & FAM & FREQ & LogFREQ & MORA \\
\hline $\mathrm{RT}_{\text {st }}$ & 1.00 & & & & & & & & & \\
\hline $\mathrm{RT}_{\text {lib }}^{\mathrm{sib}}$ & $.95^{* *}$ & 1.00 & & & & & & & & \\
\hline $\mathrm{NA}_{\mathrm{st}}$ & $-.69^{* *}$ & $-.68^{* *}$ & 1.00 & & & & & & & \\
\hline $\mathrm{NA}_{\mathrm{lib}}^{\mathrm{sib}}$ & $-.73^{* *}$ & $-.77^{* *}$ & $.64^{* *}$ & 1.00 & & & & & & \\
\hline$H$ & $.67^{* *}$ & $.71^{* *}$ & $-.83^{* *}$ & $-.65^{* *}$ & 1.00 & & & & & \\
\hline AoA & $.51^{* *}$ & $.50^{* *}$ & $-.56^{* *}$ & $-.48^{* *}$ & $.57^{* *}$ & 1.00 & & & & \\
\hline FAM & $-.38^{* *}$ & $-.36^{* *}$ & $.32^{* *}$ & $.31^{* *}$ & $-.24^{* *}$ & $-.58^{* *}$ & 1.00 & & & \\
\hline FREQ & $-.18^{* *}$ & $-.19^{* *}$ & $.16^{*}$ & .12 & $-.16^{*}$ & $-.29^{* *}$ & $.33^{* *}$ & 1.00 & & \\
\hline LogFREQ & $-.35^{* *}$ & $-.37^{* *}$ & $.33^{* *}$ & $.39^{* *}$ & $-.33^{* *}$ & $-.47^{* *}$ & $.52^{* *}$ & $.61^{* *}$ & 1.00 & \\
\hline MORA & $.19^{* *}$ & $.20^{* *}$ & $-.20^{* *}$ & $-.18^{* *}$ & $.23^{* *}$ & $.40^{* *}$ & $-.18^{* *}$ & $-.25^{* *}$ & $-.34^{* *}$ & 1.00 \\
\hline
\end{tabular}

Note $-\mathrm{RT}_{\mathrm{st}}$, naming time using strict criteria $(n=359) ; \mathrm{RT}_{\text {lib }}$, naming time using liberal criteria $(n=359)$; $\mathrm{NA}_{\mathrm{s}}$, name agreement using strict criteria $(n=359) ; \mathrm{NA}_{\text {lib }}$, name agreement using liberal criteria $(n=359) ; H$, statistics of name disagreement; AoA, age of acquisition ( $n=359)$; FAM, familiarity $(n=359)$; FREQ, frequency $(n=236)$; LogFREQ, $\log$ frequency $(n=236)$; MORA, number of morae $(n=359) . \quad{ }^{*} p<.05 .{ }^{* *} p<.01$.

itself, rather than on the basis of the word used to name it (Sanfeliu \& Fernandez, 1996).

\section{Multiple Regression Analysis}

Simultaneous multiple regression analyses were carried out on $\mathrm{RT}_{\text {st }}$, using AoA, FAM, LogFREQ, MORA, and one of the three measures of NA $\left(\mathrm{NA}_{\mathrm{st}}, \mathrm{NA}_{\mathrm{lib}}\right.$, and $H)$ as predictor variables. The pictures for which we could not obtain frequency data were excluded from the analyses. Table 3 shows the results. Regardless of which variable was used as the measure of NA, all the equations were significant (all $p \mathrm{~s}<.01$ ). The equation with $\mathrm{NA}_{\text {lib }}$ showed the highest multiple $R$. In the equation with $\mathrm{NA}_{\text {lib }}$, the variable that contributed the most was $\mathrm{NA}_{\mathrm{lib}}$, followed by AoA. FAM, LogFREQ, and MORA were not significant. In the equation including $\mathrm{NA}_{\mathrm{st}}$, the most reliable source of variance was $\mathrm{NA}_{\mathrm{st}}$. AoA, FAM, LogFREQ, and MORA were not significant. In the equation with $H$, $H$ made the greatest contribution, and the next was FAM. AoA, LogFREQ, and MORA were not significant.

Taken together, these results indicate that the most reliable predictors were the measures of NA $\left(\mathrm{NA}_{\mathrm{st}}, \mathrm{NA}_{\text {lib }}, H\right)$, which is similar to the findings in studies of French (Alario et al., 2004), American English (Snodgrass \& Yuditsky, 1996), Spanish (Cuetos et al., 1999), and Welsh (Barry, Morrison, \& Ellis, 1997). Among the three measures of
$\mathrm{NA}, \mathrm{NA}_{\text {lib }}$ contributed the most to account for $\mathrm{RT}_{\text {st }}$. This result is similar to that in Snodgrass and Yuditsky (1996), where the most significant source of variance was concept agreement, which is the percentage of participants who gave the dominant name or its synonym. This measure resembles $\mathrm{NA}_{\mathrm{lib}}$, the percentage of participants giving the name that at least 2 participants gave, because in most cases responses that were correct according to this liberal criterion shared identical meanings.

Second, whether AoA or FAM reached a significant level depended on which variable was used as the measure of NA. When $H$ was used, FAM was significant, whereas AoA was not significant. In contrast, when $\mathrm{NA}_{\text {lib }}$ was used, AoA was significant but FAM was not. When $\mathrm{NA}_{\mathrm{st}}$ was used, neither FAM nor AoA was significant. These results are inconsistent with those in the previous studies, which showed AoA to be a robust predictor (e.g., Alario et al., 2004; Bonin, Chalard, Méot, \& Fayol, 2002; Cuetos et al., 1999; Snodgrass \& Yuditsky, 1996). Therefore, to estimate the possible influence of AoA on naming time, we temporarily excluded FAM from the analysis, but AoA was not significant in the equations with $\mathrm{NA}_{\text {st }}$ and $H$. A possible reason for the unstable effect of AoA is that both FAM and AoA in the present study were rated for the concepts depicted in the pictures. However, in the other studies, FAM was rated for the concepts, whereas AoA was

Table 2

Correlations Among the Measures in the Present Study and Foreign Samples From Previous Studies

\begin{tabular}{lccccccccc}
\hline & $\mathrm{RT}_{\text {st }}$ & $\mathrm{RT}_{\text {lib }}$ & $\mathrm{NA}_{\mathrm{st}}$ & $\mathrm{NA}_{\text {lib }}$ & $H$ & AoA & FAM & FREQ & \multicolumn{2}{l}{$\operatorname{LogFREQ}$} \\
\hline American (S\&Y) & $.56^{* *}$ & $.60^{* *}$ & $.27^{* *}$ & $.50^{* *}$ & - & $.70^{* *}$ & - & - & - \\
American (S\&V) & - & - & $.29^{* *}$ & $.35^{* *}$ & $.38^{* *}$ & $.66^{* *}$ & $.78^{* *}$ & $.51^{* *}$ & $.61^{* *}$ \\
Spanish & $.39^{* *}$ & $.39^{* *}$ & $.20^{*}$ & $.16^{\dagger}$ & - & $.59^{* *}$ & $.83^{* *}$ & .18 & $.58^{* *}$ \\
French & - & - & $.34^{* *}$ & $.31^{* *}$ & $.40^{* *}$ & $.64^{* *}$ & $.80^{* *}$ & $.44^{* *}$ & $.54^{* *}$ \\
Icelandic & - & - & $.16^{*}$ & $.14^{*}$ & $.28^{* *}$ & $.56^{* *}$ & $.77^{* *}$ & $.67^{* *}$ & $.56^{* *}$ \\
\hline
\end{tabular}

Note-Samples were collected for American English [American (S\&Y), Snodgrass \& Yuditsky, 1996; American (S\&V), Snodgrass \& Vanderwart, 1980]; Spanish (Cuetos, Ellis, \& Alvarez, 1999); French (Alario \& Ferrand, 1999);

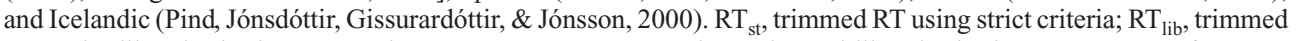
RT under liberal criteria; $\mathrm{NA}_{\text {st }}$ and $\mathrm{NA}_{\text {lib }}$, name agreement using strict and liberal criteria; $H$, a measure for name disagreement; AoA, age of acquisition; FAM, familiarity; FREQ, frequency; LogFREQ, $\log$ frequency. Dashes indicate that data were not available. LogFREQ of Spanish sample was from fAC (adult word frequency) in Cuetos et al. (1999). $\quad{ }^{*} p<.05 . \quad{ }^{* *} p<.01 . \quad{ }^{\dagger} p<.10$. 
Table 3

Multiple Regression Analyses

\begin{tabular}{|c|c|c|c|c|c|c|}
\hline & $\begin{array}{c}\text { Beta } \\
\text { Weight }\end{array}$ & $t$ Value & $\begin{array}{c}\text { Beta } \\
\text { Weight }\end{array}$ & $t$ Value & $\begin{array}{l}\text { Beta } \\
\text { Weight }\end{array}$ & $t$ Value \\
\hline $\mathrm{NA}_{\mathrm{st}}$ & -.59 & $-10.26^{* *}$ & - & - & - & - \\
\hline $\mathrm{NA}_{\text {lib }}$ & - & - & -.64 & $-12.50^{* *}$ & - & - \\
\hline$H$ & - & - & - & - & .58 & $9.64^{* *}$ \\
\hline FAM & -.10 & -1.59 & -.08 & -1.49 & -.17 & $-2.72^{* *}$ \\
\hline AoA & .06 & 0.81 & .12 & $2.05^{*}$ & .02 & 0.32 \\
\hline LogFREQ & -.06 & -1.03 & .01 & 0.17 & -.05 & -0.76 \\
\hline MORA & .05 & 0.89 & .02 & 0.47 & .04 & 0.67 \\
\hline$R^{2}$ & \multicolumn{2}{|c|}{.50} & \multicolumn{2}{|c|}{.57} & \multicolumn{2}{|c|}{.48} \\
\hline$F$ value & \multicolumn{2}{|c|}{$46.01^{* *}$} & \multicolumn{2}{|c|}{$60.06^{* *}$} & \multicolumn{2}{|c|}{$42.64^{* *}$} \\
\hline
\end{tabular}

Note $-\mathrm{NA}_{\mathrm{st}}$, name agreement under strict criteria; $\mathrm{NA}_{\text {lib }}$, name agreement under liberal criteria; $H$, a measure for name disagreement; FAM, familiarity; AoA, age of acquisition; LogFREQ, $\log$ frequency; MORA, number of morae. ${ }^{*} p<.05 . \quad{ }^{* *} p<.01$.

rated for the names of the pictures (Alario et al., 2004; Cuetos et al., 1999; Dell'Acqua et al., 2000; Pind et al., 2000; Snodgrass \& Yuditsky, 1996).

Third, LogFREQ did not make a significant contribution, as was also shown in Dell'Acqua et al. (2000). This might be attributed to the nature of the FREQ data used in our study. The corpus of the newspaper may not adequately represent the various texts that readers are exposed to. In addition, the FREQ used in our study did not take account of childhood data. Bonin, Barry, Méot, and Chalard (2004) reported that naming time was predicted by cumulative FREQ of exposure throughout a lifetime, including childhood. Finally, MORA was not a significant predictor, similar to the findings in several studies in which number of syllables or phonemes was used as a predictor (Bonin et al., 2002; Bonin et al., 2003; Dell'Acqua et al., 2000).

\section{CONCLUSIONS}

The main goal of the present study was to develop a Japanese normative set of pictures and to compare the data with those in preceding studies from different cultures. A total of 359 pictures, including 260 from Snodgrass and Vanderwart (1980), were adopted for standardization. Forty-four pictures of the 260 were redrawn for Japanese audiences, and 99 were newly added. Variables such as naming time, NA, FAM, and AoA were measured for standardization.

The correlation of data from our study with data from investigations of four different cultures (American, French, Spanish, and Icelandic) was relatively high for almost all the measures, except for NA. The most reliable predictors of naming times were three measures of NA-namely, $\mathrm{NA}_{\mathrm{st}}, \mathrm{NA}_{\mathrm{lib}}$, and $H$, especially $\mathrm{NA}_{\text {lib }}$. In addition, either AoA or FAM was a significant predictor, depending on which measure of NA $\left(\mathrm{NA}_{\mathrm{st}}, \mathrm{NA}_{\mathrm{lib}}\right.$, or $H$ ) was adopted as an independent variable. The present Japanese normative measures for the 359 pictures can be used in research with Japanese-speaking participants. These pictures will be useful for researchers in different fields of experimental psychology, such as attention, memory, perception, cognitive neuropsychology, and language.

\section{REFERENCES}

Alario, F.-X., \& Ferrand, L. (1999). A set of 400 pictures standardized for French: Norms for name agreement, image agreement, familiarity, visual complexity, image variability, and age of acquisition. Behavior Research Methods, Instruments, \& Computers, 31, 531-552.

Alario, F.-X., Ferrand, L., Laganaro, M., New, B., Frauenfelder, U. H., \& SEGUI, J. (2004). Predictors of picture naming speed. Behavior Research Methods, Instruments, \& Computers, 36, 140-155.

Amano, S., \& Kondo, T. (2000). Nihongo-no goi-tokusei [Lexical properties of Japanese] (Vol. 7). Tokyo: Sanseido.

Barry, C., Morrison, C. M., \& Ellis, A. W. (1997). Naming the Snodgrass and Vanderwart pictures: Effects of age of acquisition, frequency, and name agreement. Quarterly Journal of Experimental Psychology, 50A, 560-585.

Bates, E., D'Amico, S., Jacobsen, T., Székely, A., Andonova, E., Devescovi, A., ET AL. (2003). Timed picture naming in seven languages. Psychonomic Bulletin \& Review, 10, 344-380.

Bonin, P., Barry, C., MÉot, A., \& Chalard, M. (2004). The influence of age of acquisition in word reading and other tasks: A never ending story? Journal of Memory \& Language, 50, 456-476.

Bonin, P., Chalard, M., MÉot, A., \& Fayol, M. (2002). The determinants of spoken and written picture naming latencies. British Journal of Psychology, 93, 89-114.

Bonin, P., Peereman, R., Malardier, N., Méot, A., \& Chalard, M. (2003). A new set of 299 pictures for psycholinguistic studies: French norms for name agreement, image agreement, conceptual familiarity, visual complexity, image variability, age of acquisition, and naming latencies. Behavior Research Methods, Instruments, \& Computers, 35, 158-167.

CARroll, J. B., \& White, M. N. (1973a). Age of acquisition norms for 220 picturable nouns. Journal of Verbal Learning \& Verbal Behavior, 12, 563-576.

Carroll, J. B., \& White, M. N. (1973b). Word frequency and age of acquisition as determiners of picture-naming latency. Quarterly Journal of Experimental Psychology, 25, 85-95.

Cuetos, F., Ellis, A. W., \& Alvarez, B. (1999). Naming times for the Snodgrass and Vanderwart pictures in Spanish. Behavior Research Methods, Instruments, \& Computers, 31, 650-658.

Cycowicz, Y. M., Friedman, D., Rothstein, M., \& Snodgrass, J. G. (1997). Picture naming by young children: Norms for name agreement, familiarity, and visual complexity. Journal of Experimental Child Psychology, 65, 171-237.

Dell'Acqua, R., LotTo, L., \& Job, R. (2000). Naming times and standardized norms for the Italian PD/DPSS set of 266 pictures: Direct comparisons with American, English, French, and Spanish published databases. Behavior Research Methods, Instruments, \& Computers, 32, 588-615.

KUČERA, H., \& FrANCIS, W. N. (1967). Computational analysis of presentday American English. Providence, RI: Brown University Press.

MatsukaWA, J. (1983). [A study of characteristics of pictorial material (1)]. [Memoirs of the Faculty of Law and Literature, Shimane University], 6, 97-139. (in Japanese)

Nishimoto, T., \& Hayashi, S. (1996). [A standardized set of 143 pictures: Norms for name agreement, image agreement, and familiarity]. [Waseda Psychological Reports], 28, 59-85. (in Japanese)

Nishimoto, T., \& YAsuda, Y. (1982). [A standardized set of 260 pictures: Japanese norms for name agreement, image agreement, and visual complexity]. [Waseda Psychological Reports], 14, 55-76. (in Japanese)

Pind, J., JónsdótTir, H., GissurardótTir, H., \& Jónsson, F. (2000). Icelandic norms for the Snodgrass and Vanderwart (1980) pictures: Name and image agreement, familiarity, and age of acquisition. Scandinavian Journal of Psychology, 41, 41-48.

Pind, J., \& TRYgGVadóttiR, H. B. (2002). Determinants of picture naming times in Icelandic. Scandinavian Journal of Psychology, 43, 221-226.

Sanfeliu, M. C., \& Fernandez, A. (1996). A set of 254 SnodgrassVanderwart pictures standardized for Spanish: Norms for name agree- 
ment, image agreement, familiarity, and visual complexity. Behavior Research Methods, Instruments, \& Computers, 28, 537-555.

SNODGRASs, J. G., \& VANDERWART, M. (1980). A standardized set of 260 pictures: Norms for name agreement, image agreement, familiarity, and visual complexity. Journal of Experimental Psychology: Human Learning \& Memory, 6, 174-215.

SNODGRASS, J. G., \& YUdITSKY, T. (1996). Naming times for the Snodgrass and Vanderwart pictures. Behavior Research Methods, Instruments, \& Computers, 28, 516-536.

Székely, A., D’Amico, S., Devescovi, A., Federmeier, K., Herron, D., IYER, G., ET AL. (2003). Timed picture naming: Extended norms and validation against previous studies. Behavior Research Methods, Instruments, \& Computers, 35, 621-633.

\section{NOTE}

1. The number of excluded participants seemed relatively large, which could influence the results. Therefore, we also conducted the same analyses of the data for the entire sample of participants and compared the results with those for the outlier-eliminated data sample. The correlations between these two samples were quite high for mean naming times and correctness $\left(\mathrm{RT}_{\mathrm{st}}=.96, \mathrm{RT}_{\text {lib }}=.97, \mathrm{NA}_{\mathrm{st}}=.99, \mathrm{NA}_{\text {lib }}=.95\right)$. The results of the regression analyses were almost the same. Therefore, we present the results only for the outlier-eliminated data set.

\section{ARCHIVED MATERIALS}

The following materials and links may be accessed through the Psychonomic Society'sNorms, Stimuli, andDataarchive, http://www.psychonomic .org/archive/.
To access these files, search the archive for this article using the journal (Behavior Research Methods), the first author's name (Nishimoto), and the publication year (2005).

FILE: Nishimoto-BRM-2005.zip

DESCRIPTION: The compressed archive file contains the following folders and files:

Nishimoto_etal_2005_appendix_a.xls, containing the norms developed by the present authors as a $217 \mathrm{~K}$ binary file generated by Microsoft Excel 2002 for Microsoft Windows. Each row represents one of 359 pictures; each column represents one of the eight dependent measures besides the names (English and Japanese), IDs, and types of the pictures. Japanese names are described in Japanese Katakana, using a Japanese font.

Nishimoto_etal_2005_appendix_a.txt, a 25K tab-delimited text file of the Nishimoto_etal_2005_appendix_a.xls. In this file, Japanese names are omitted.

Nishimoto_etal_2005_about_appendix_a.txt, a full description of the content of Nishimoto_etal_2005_appendix_a.xls, including extended definitions of the columns of the norm (a $2 \mathrm{~K}$ plain text file).

Nishimoto_etal_2005_appendix_b_summary.pdf, including the thumbnails of all pictures $(8,035 \mathrm{~K})$.

appendix_b, a 4,755K folder including 143 jpeg-format files (XXX. jpg) of the redrawn or newly added pictures from Snodgrass and Vanderwart (1980). The numbers in the name of each file correspond to the picture numbers in Appendices A and B of Nishimoto et al. (2005), or Nishimoto_etal_2005_appendix_a.xls.

AUTHOR’s E-MAIL ADDRESS: nishi@waseda.jp. 


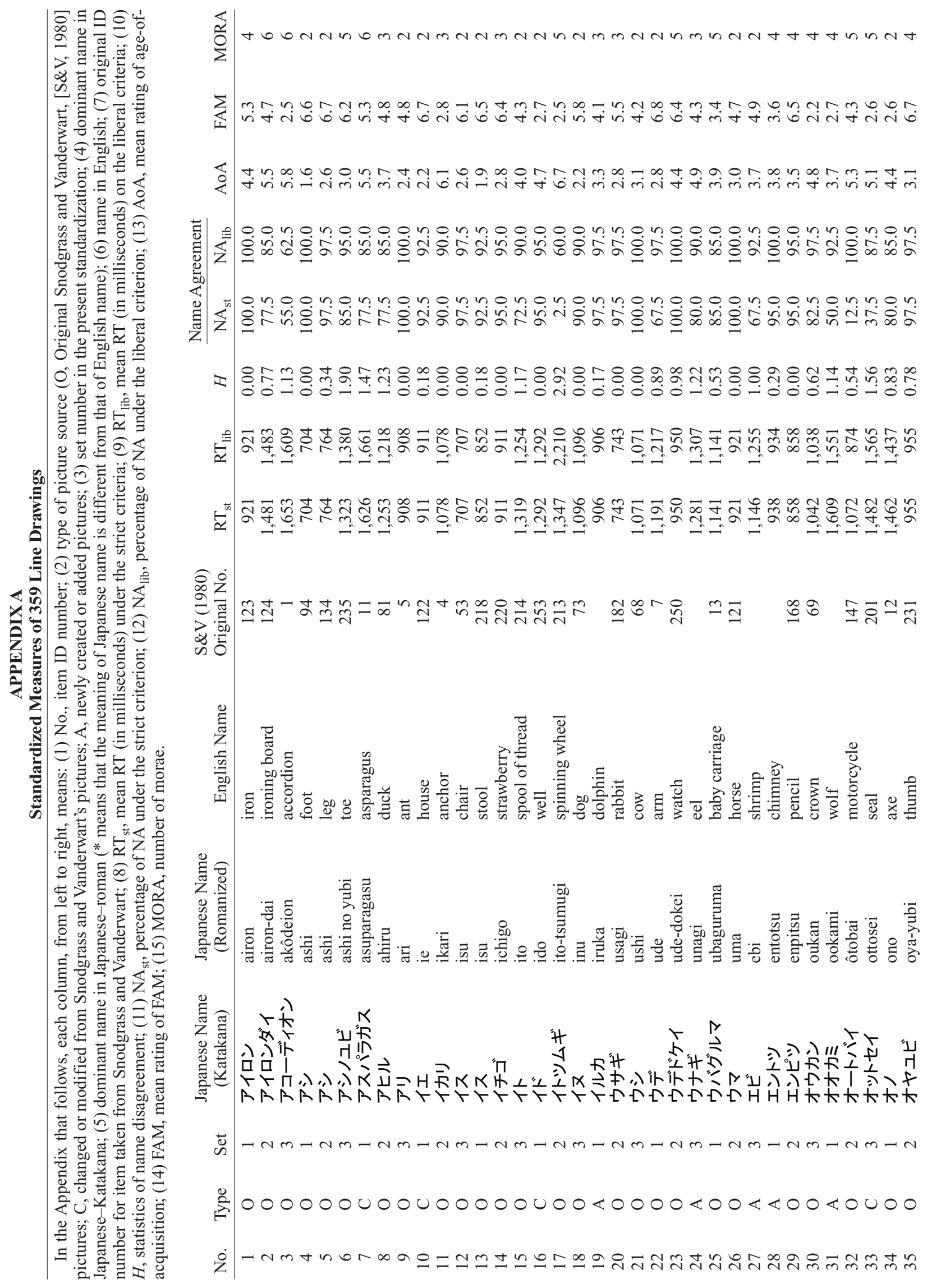




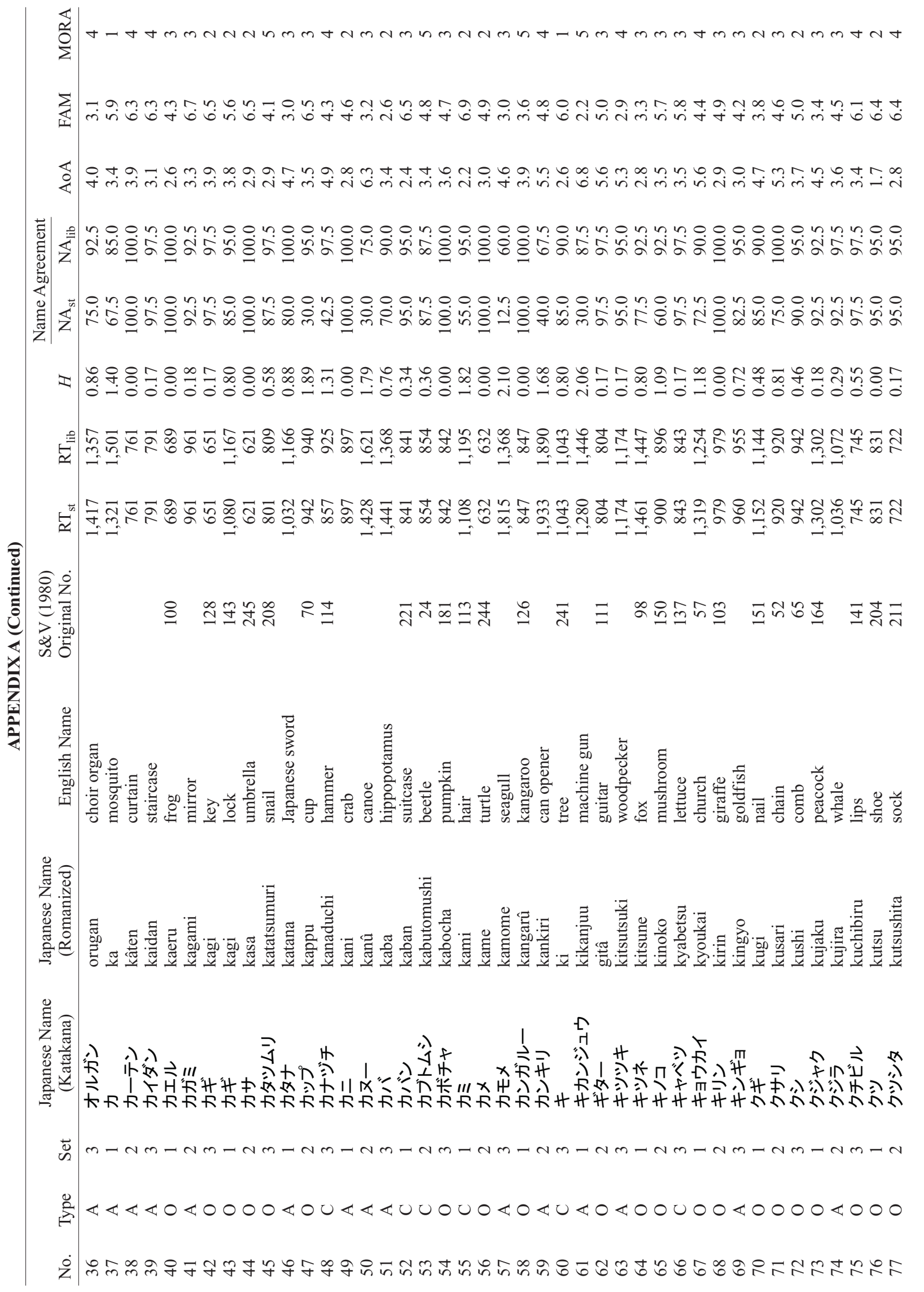




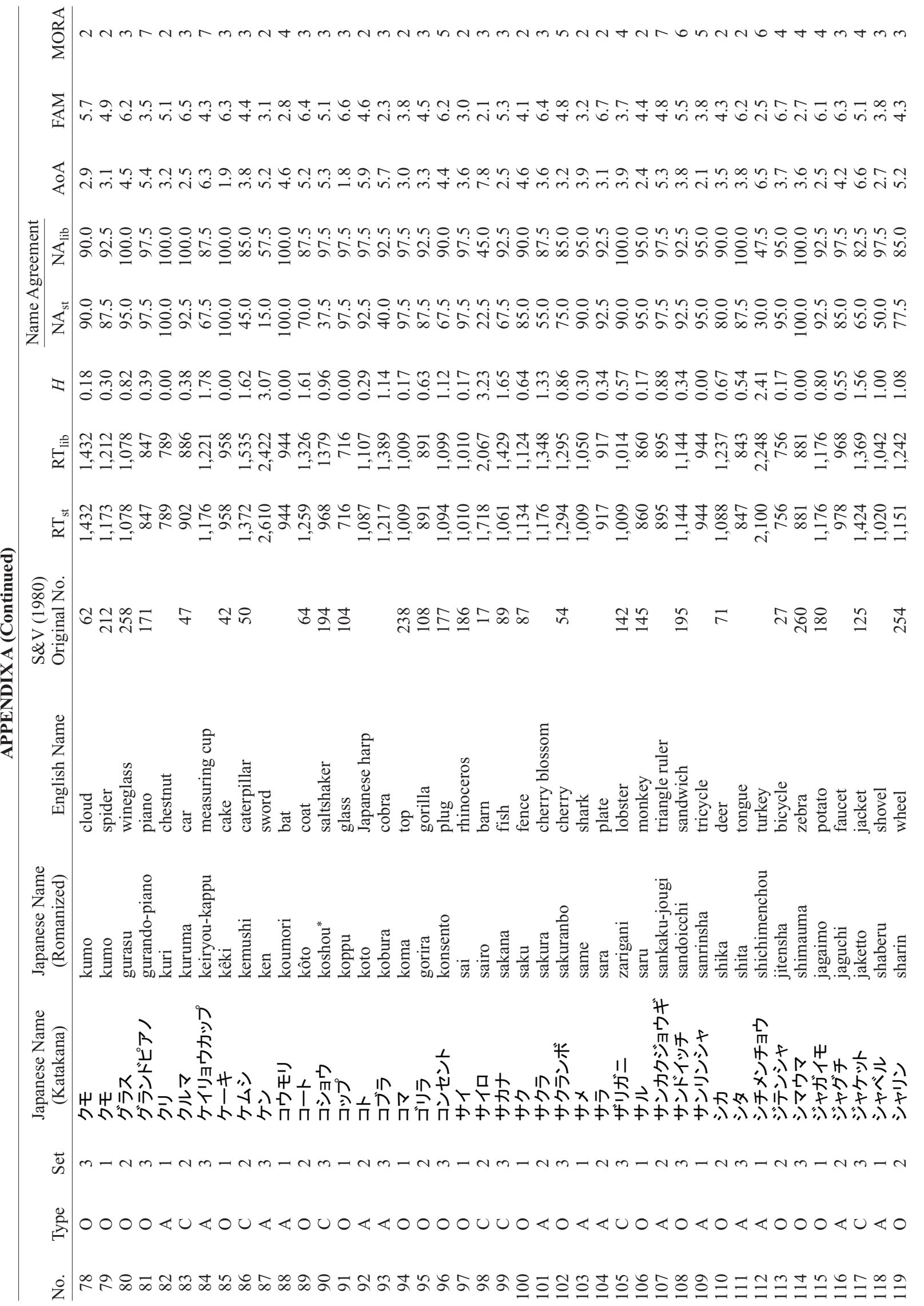




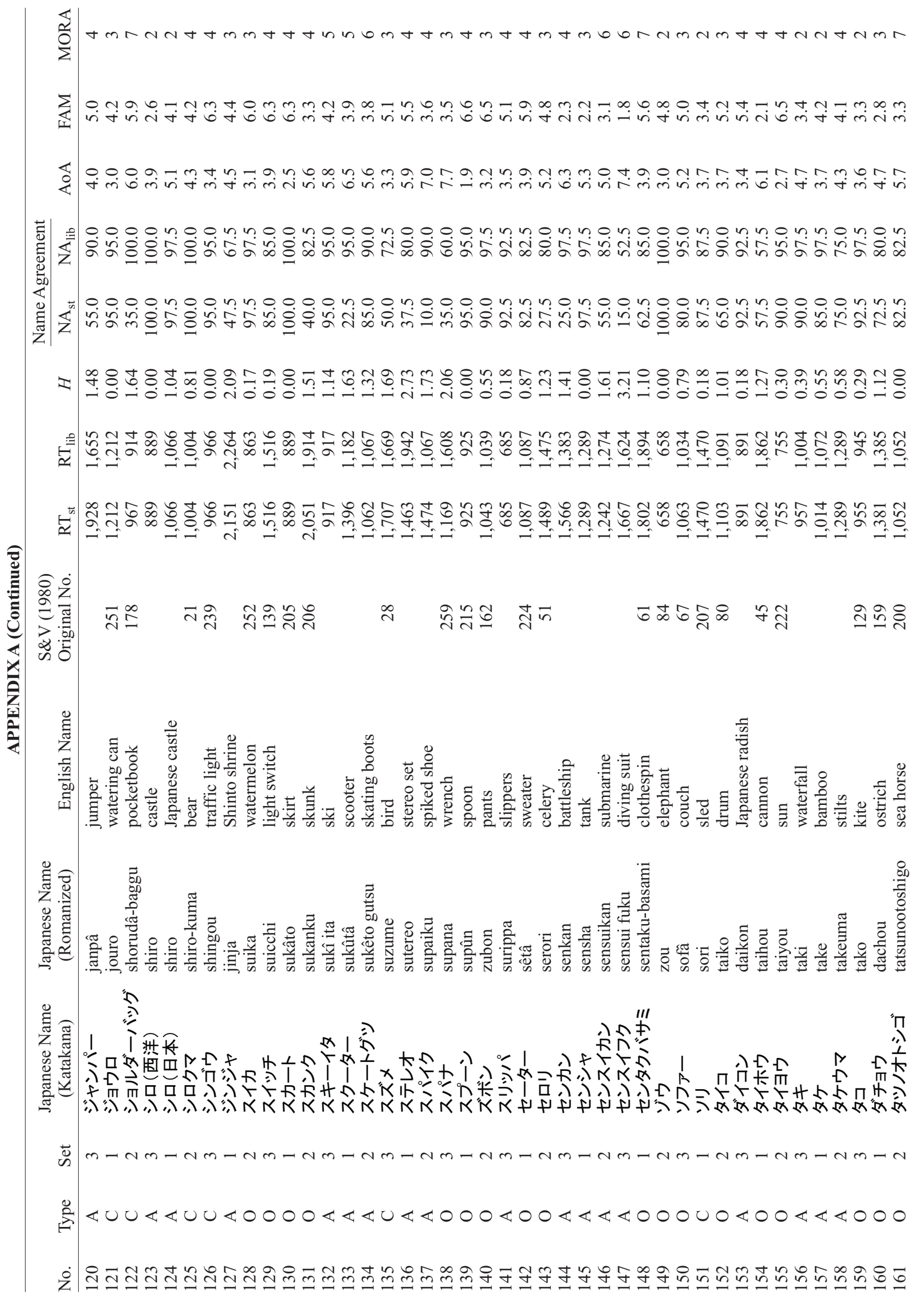




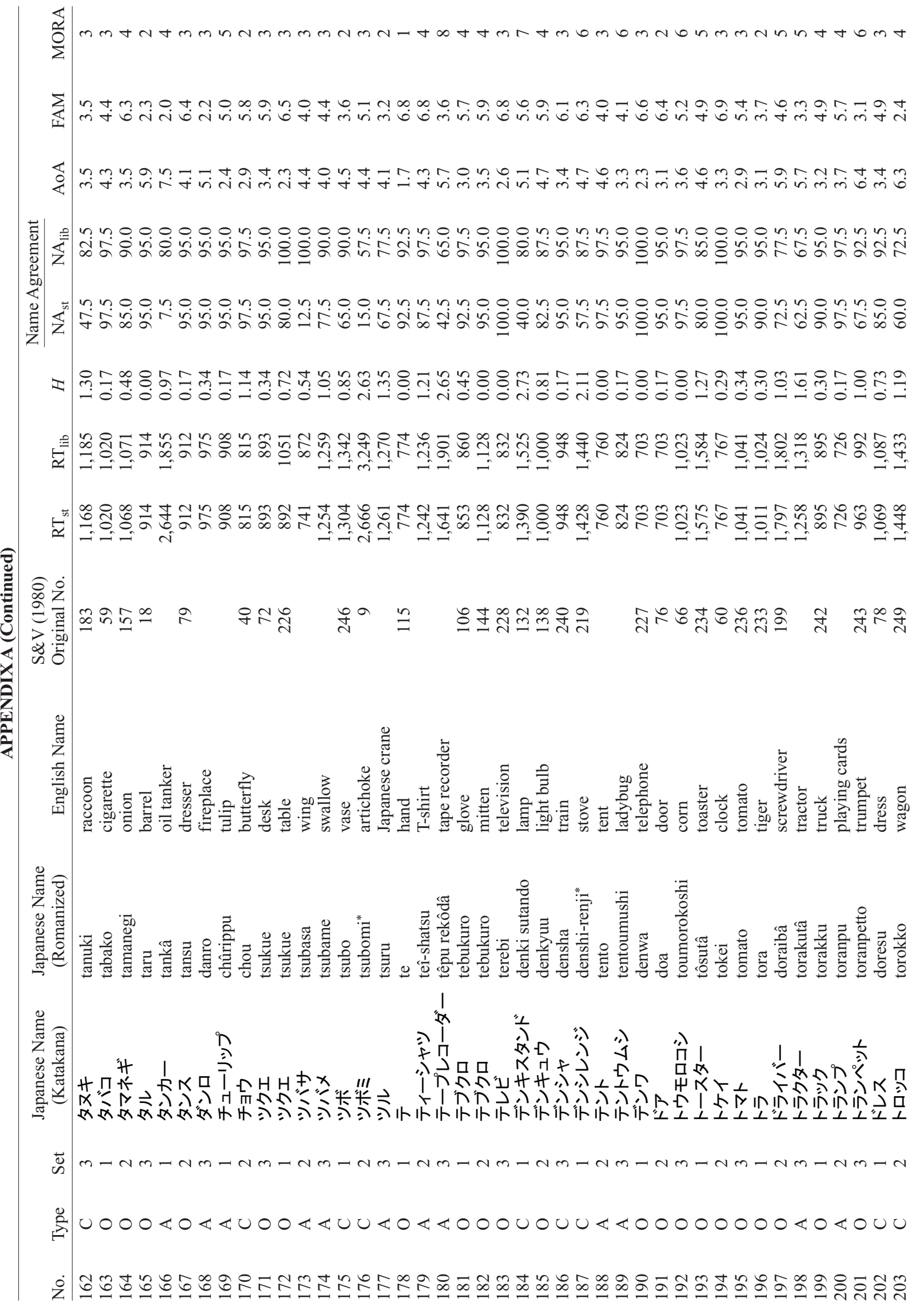




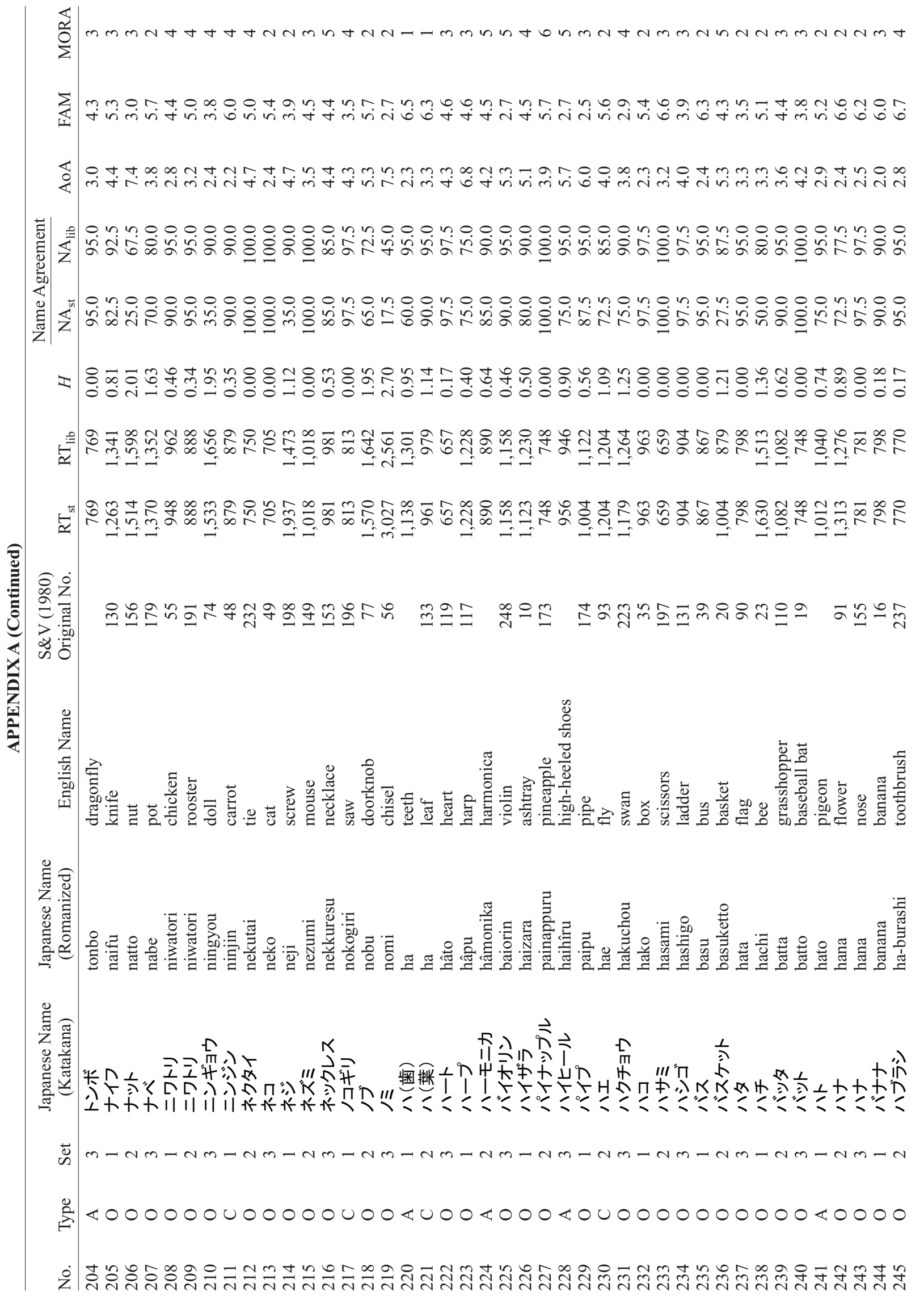




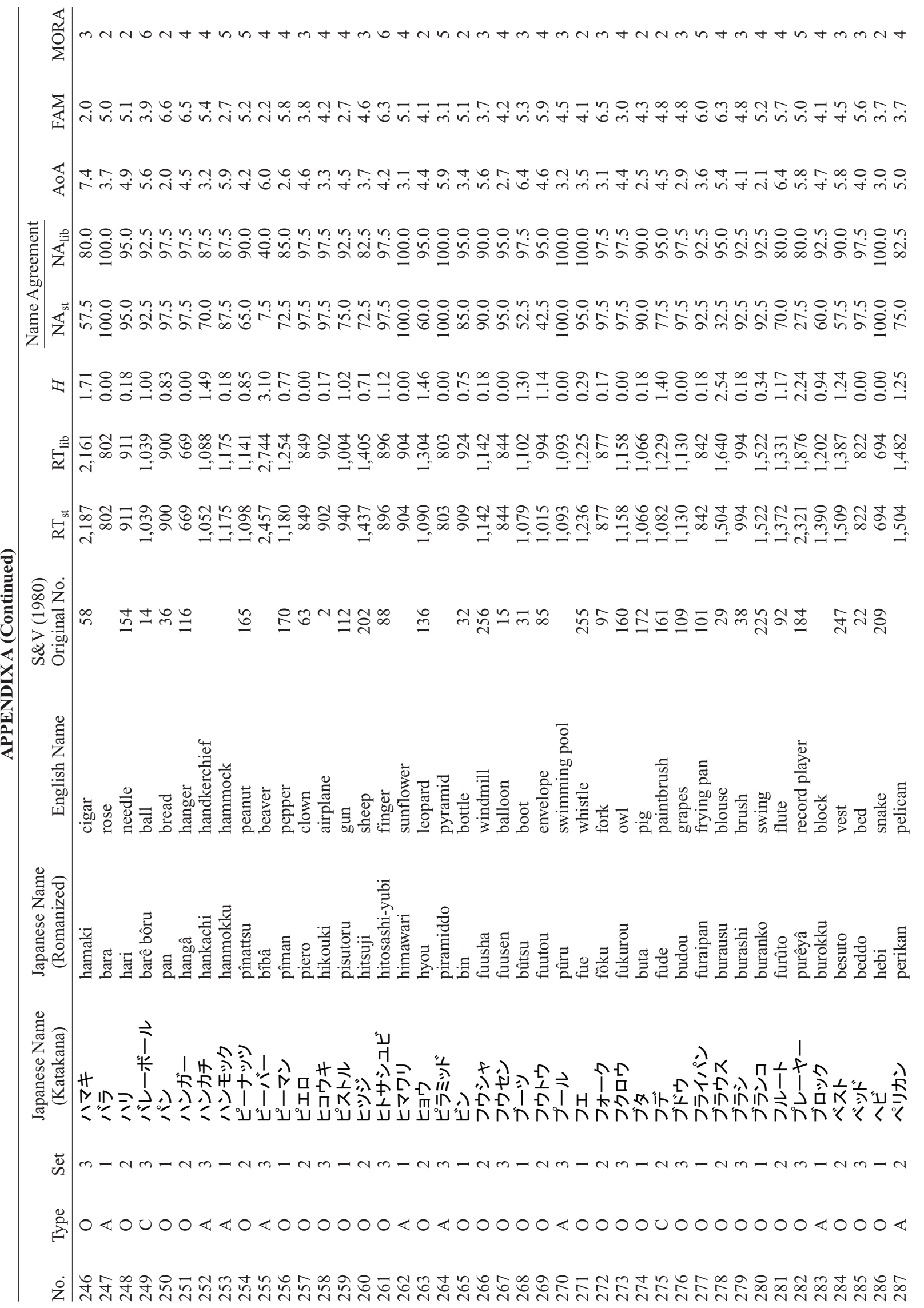




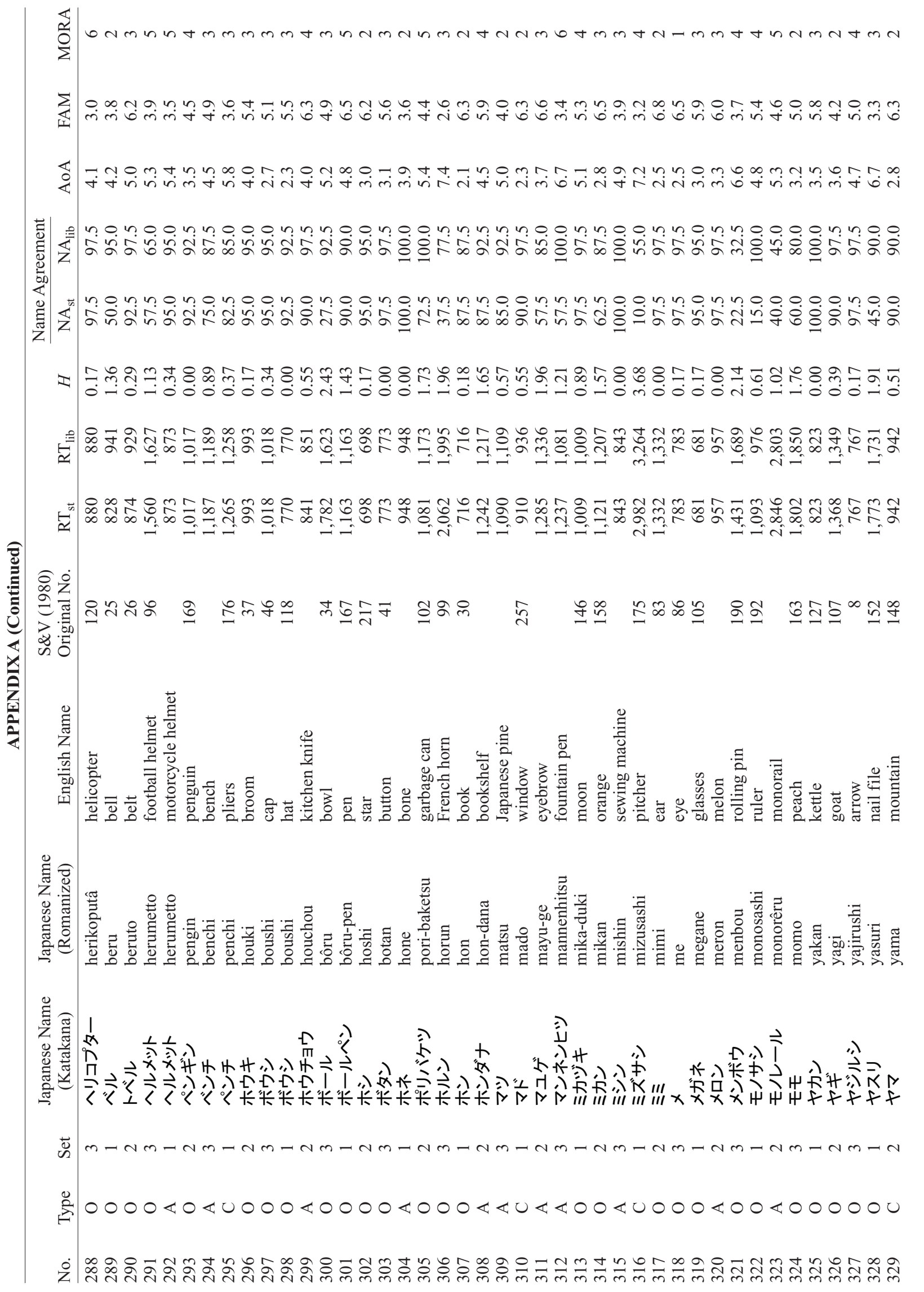




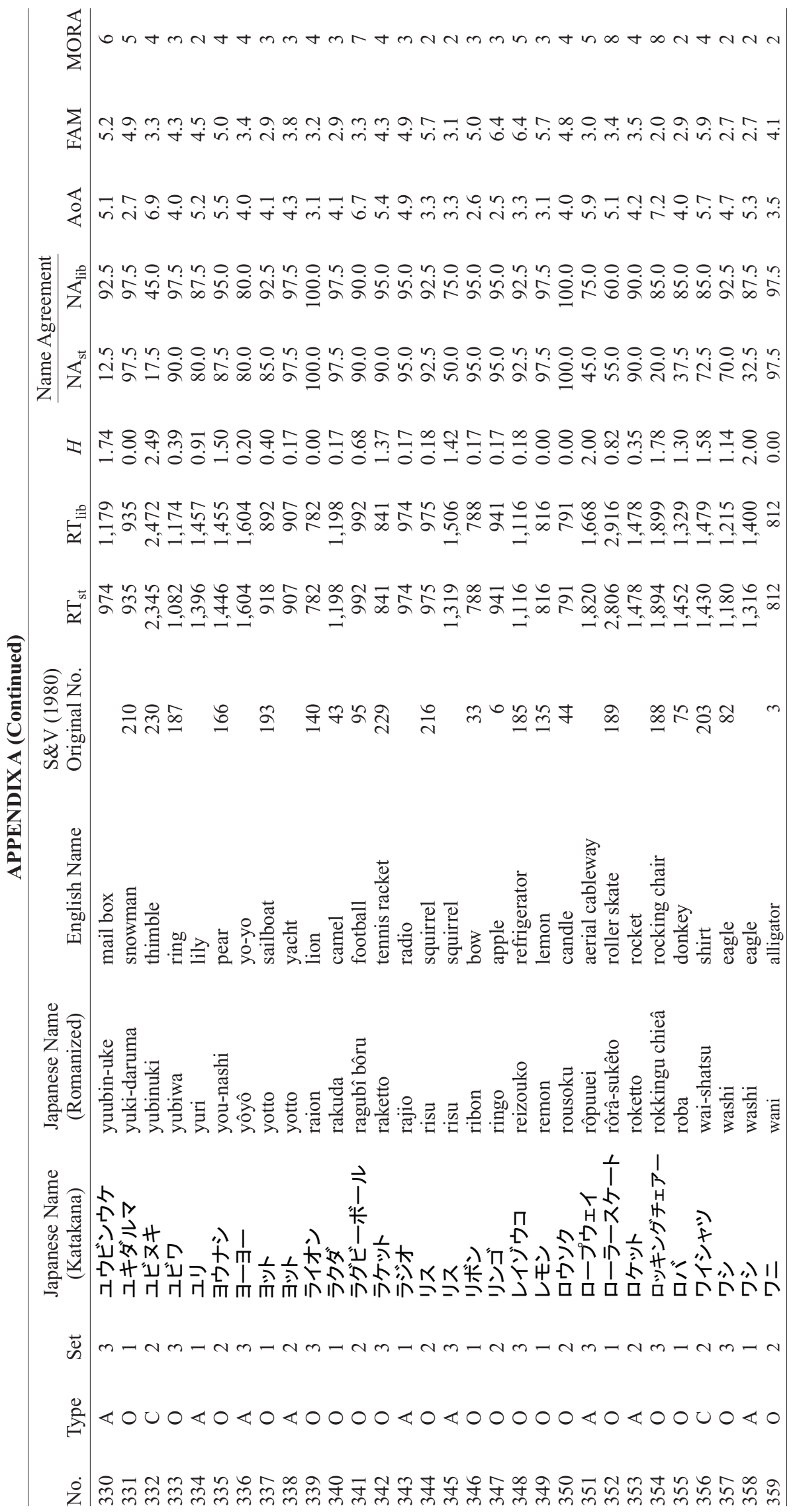


APPENDIX B

Redrawn or Newly Added Pictures From Snodgrass and Vanderwart (1980)

Redrawn or newly added pictures from Snodgrass and Vanderwart (1980) are listed. These are provided by Nishimoto and Hayashi (1996). The number under each picture shows the item number (see Appendix A for details).

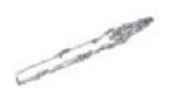

7

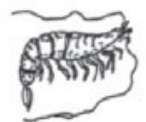

27

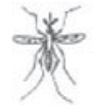

37

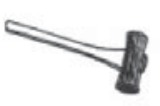

48

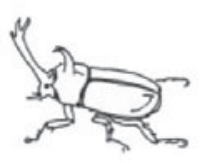

53

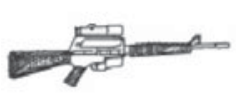

61

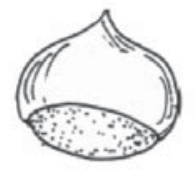

82

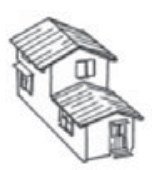

10

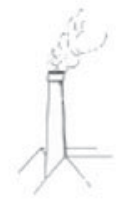

28

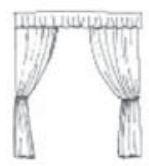

38

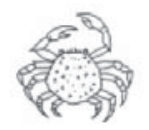

49

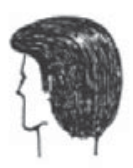

55

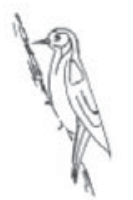

63

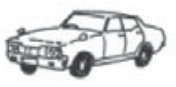

83

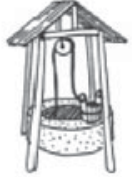

16

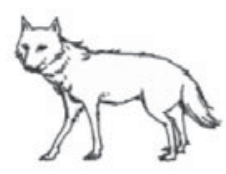

31

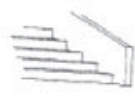

39

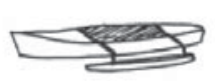

50

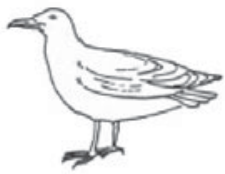

57

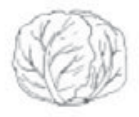

66

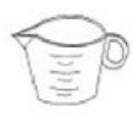

81

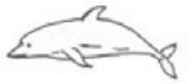

19

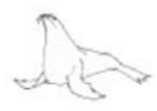

33

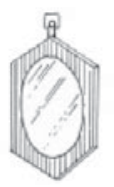

41

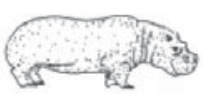

51

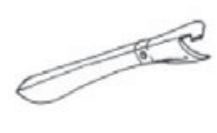

59

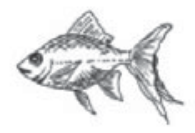

69

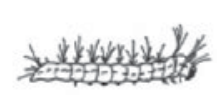

86

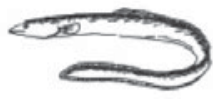

24

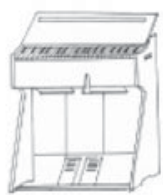

36

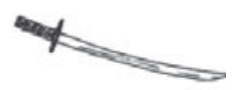

46

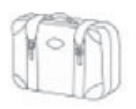

52

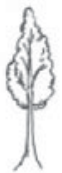

60

74 
414 NISHIMOTO, MIYAWAKI, UEDA, UNE, AND TAKAHASHI

APPENDIX B (Continued)

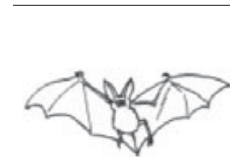

88

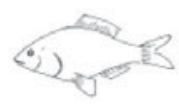

99

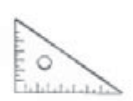

107

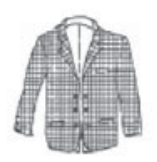

117

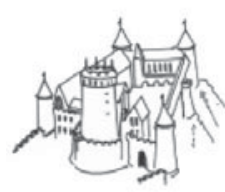

123

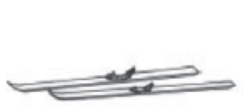

132

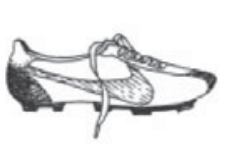

137

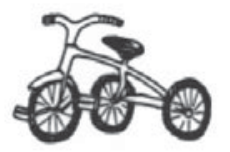

109

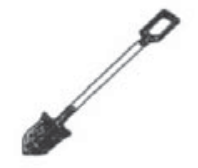

118

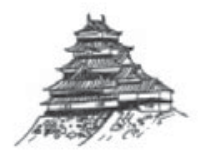

124

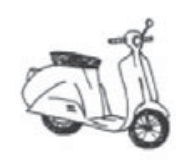

133

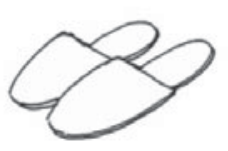

141

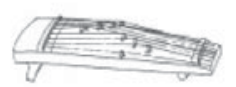

92

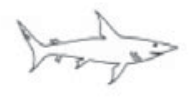

103

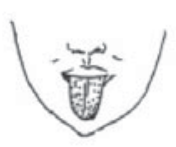

111

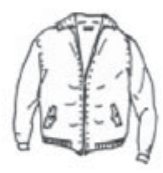

120

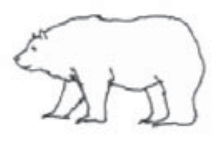

125

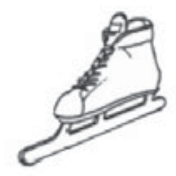

134

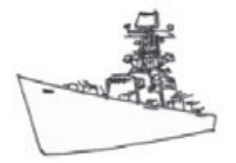

144

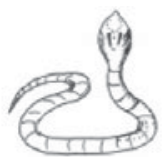

93

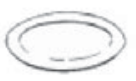

104

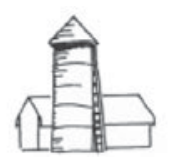

98

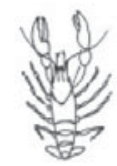

105

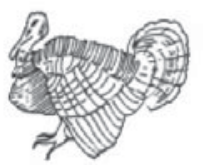

112

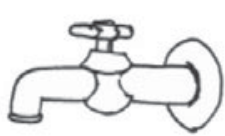

116

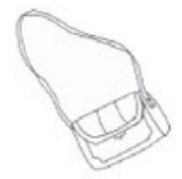

121

122

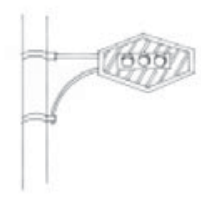

126

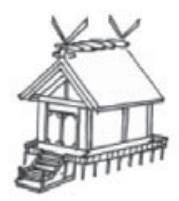

127 
APPENDIX B (Continued)

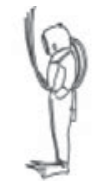

147

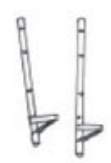

158

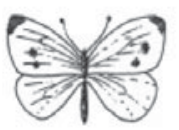

170

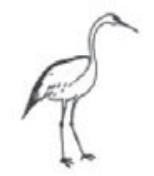

177

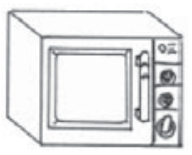

187

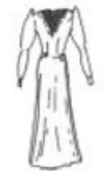

202

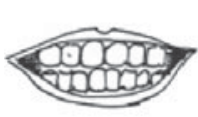

220

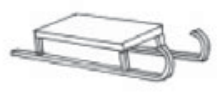

151

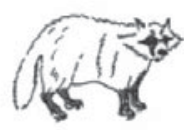

162

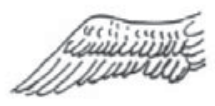

173

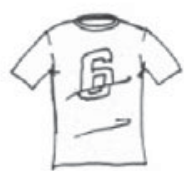

179

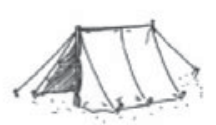

188

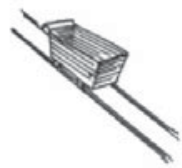

203

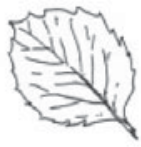

221

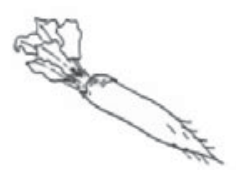

153

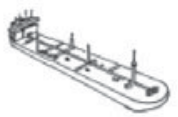

166

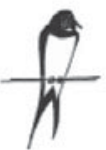

174

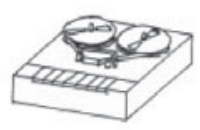

180

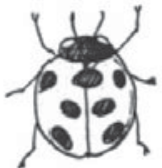

189

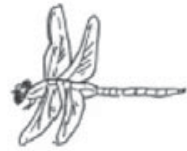

204

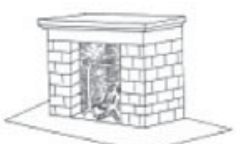

168

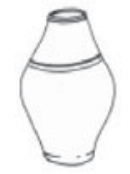

175

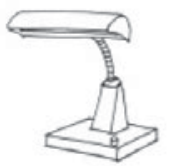

184

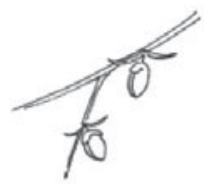

176

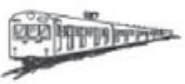

186

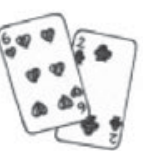

198

200

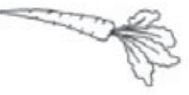

211

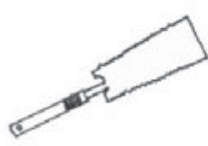

217
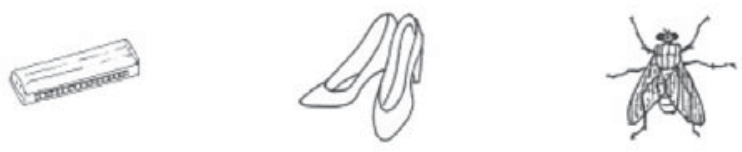

224

228

230 
APPENDIX B (Continued)

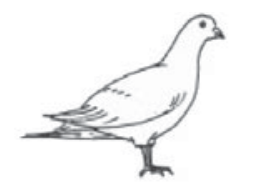

241

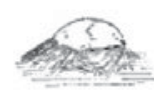

255

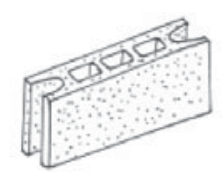

283

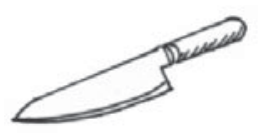

299

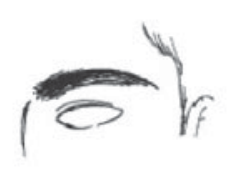

311

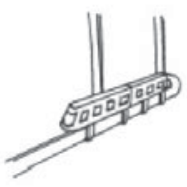

323

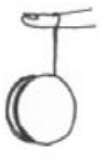

336

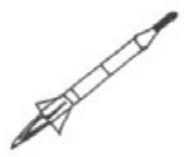

353

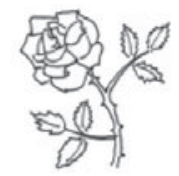

247

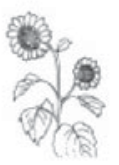

262

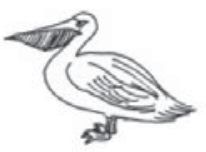

287

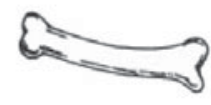

304

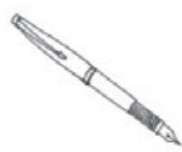

312

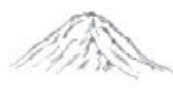

329

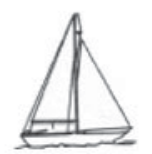

338

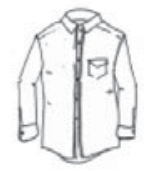

356

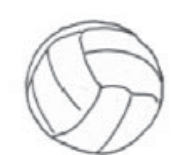

249

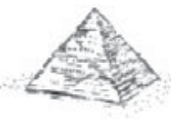

264

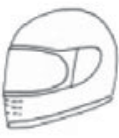

292

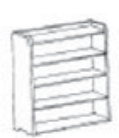

308

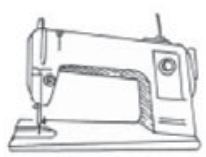

315

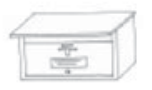

330

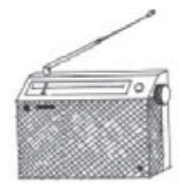

343

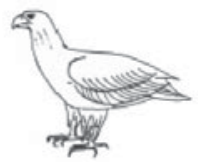

358
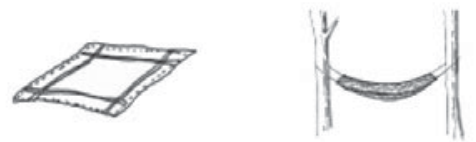

253

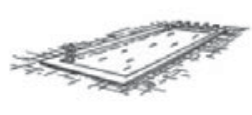

270

275
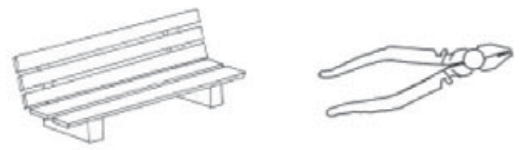

294

295
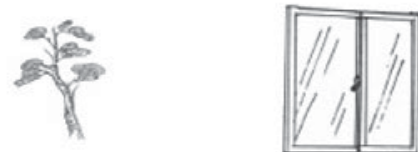

309

310

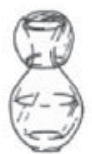

316

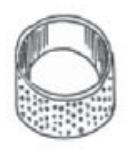

332

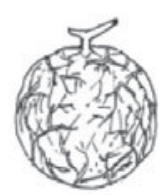

320

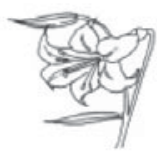

334

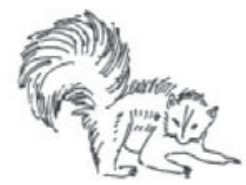

345

351 